\title{
Optimización de parámetros para la elaboración de leche ácida con Lactobacillus acidophilus
}

\author{
Katherin R. Taco y Paula García-Godos* \\ Facultad de Ciencias Biológicas, Universidad Nacional de San Cristóbal de Huamanga, Portal Independencia № 57. \\ Ayacucho - Perú. (Correo-e: katherin.rtq@gmail.com; paulagga30@hotmail.com) \\ ${ }^{*}$ Autor a quien debe ser dirigida la correspondencia
}

Recibido Ago. 18, 2020; Aceptado Oct. 14, 2020; Versión final Nov. 18, 2020, Publicado Feb. 2021

\begin{abstract}
Resumen
El objetivo de esta investigación fue optimizar los parámetros de fermentación y el agente conservante para la elaboración de leche ácida con Lactobacillus acidophilus. L. acidophilus se inoculó en leche, incubándose a 42, 45 y 50 grados Celsius por 8, 10 y 12 horas. Los mejores parámetros de fermentación se observaron a $10^{8} \mathrm{UFC} / \mathrm{mL}$ a $45^{\circ} \mathrm{C}$ durante 8 horas, obteniendo un $\mathrm{pH}$ final de 4.5 y una acidez titulable de $90^{\circ} \mathrm{D}$. El mejor agente conservante para la leche ácida almacenada sin refrigeración fue el benzoato de sodio $(0,1 \%)$ con el $98 \%$ de aceptación. Y para las almacenadas en refrigeración, el benzoato de sodio $(0.1 \%)$ y de sorbato de potasio $(0.1 \%)$ tuvieron un $100 \%$ de aceptación en los sabores de durazno y chirimoya y ambos presentaron una vida anaquel de 35 días y una carga microbiana de $10^{9} \mathrm{UFC} / \mathrm{mL}$. Se concluye que se logró optimizar la elaboración de leche ácida con $L$. acidophilus y que ésta cumple con lo establecido para ser considerada apta para el consumo humano y como bebida probiótica.
\end{abstract}

Palabras clave: leche ácida; Lactobacillus acidophilus; probióticos; fermentación; agente conservante

\section{Optimizing parameters for acid milk production with Lactobacillus acidophilus}

\begin{abstract}
The objective of this research study was to optimize fermentation parameters and the preservative agent for the production of acid milk with Lactobacillus acidophilus. Milk inoculated with L. acidophilus was incubated at 42 , 45 , and $50{ }^{\circ} \mathrm{C}$ for 8,10 , and 12 hours. The best fermentation parameters were observed with $10^{8} \mathrm{UFC} / \mathrm{mL}$ at $45^{\circ} \mathrm{C}$ for 8 hours, obtaining a final $\mathrm{pH}$ of 4.5 and a titratable acidity of $90^{\circ} \mathrm{D}$. The best preservative agent for sour milk stored without refrigeration was sodium benzoate $(0.1 \%)$ with $98 \%$ acceptance. The best preservative agents for refrigeration were sodium benzoate $(0.1 \%)$ and potassium sorbate $(0.1 \%)$ with $100 \%$ acceptance in peach and custard apple flavors. Both preservatives showed a shelf life of 35 days and a microbial load of $10^{9} \mathrm{UFC} / \mathrm{mL}$. It is concluded that the optimization method developed here succeeded in elaborating acid milk inoculated with $L$. acidophilus that meets the standards for human consumption and as a probiotic drink.
\end{abstract}




\section{INTRODUCCIÓN}

El desarrollo de alimentos funcionales ha constituido una oportunidad para mejorar la calidad de la dieta y la selección óptima de los alimentos que afectan positivamente a la salud y el bienestar del individuo. Así las diferentes investigaciones nos han mostrado que los productos lácteos fermentados representan una excelente fuente para una gama de probióticos que dan un valor positivo a la leche (Farag et al., 2019). Estos forman parte de una dieta saludable y balanceada, ya que contienen micro y macronutrientes y una mayor disponibilidad, porque contienen microorganismos que favorecen a la microbiota intestinal, los cuales actúan desplazando a los patógenos y también intervienen en los mecanismos de inmunomodulación, por lo que su consumo debe realizarse desde los primeros años de vida (Tojo et al., 2006).

Los probióticos orales son microorganismos vivos que después de su ingestión en número específico, ejercen beneficios para la salud del huésped, más allá de aquellos que son inherentes a la nutrición básica (Valdonio et al., 2017), los cuales producen efectos benéficos en la salud de los consumidores. Los beneficios terapéuticos percibidos han llevado a incrementar la proporción de bacterias probióticas, tales como Lactobacillus $s p$ en productos lácteos como la leche ácida y el yogurt y para lograr los efectos benéficos, los cuales deben ser metabólicamente estables y activos, tanto en el producto alimenticio, como en el huésped (Kailasapathy y Chin, 2000).

Estudios han mostrado que la viabilidad de bacterias probióticas en las leches fermentadas resulta ser menor al umbral terapéutico $\left(10^{8} \mathrm{UFC} / \mathrm{mL}\right)$, de la cantidad necesaria de microorganismos probióticos requerida para que los efectos benéficos sean percibidos por el huésped (López-Rubio et al., 2006). La leche de vaca contiene galactooligosacáridos, siendo ésta una sustancia prebiótica, por ello es un sustrato para los probióticos que confieren beneficio en la salud del huésped, asociado con la modulación de la microbiota, por lo que deben de cumplir requisitos como no ser hidrolizado ni absorbido en la parte superior del tracto gastrointestinal; ser fermentado selectivamente en el colon por un número limitado de bacterias con potencial benéfico (principalmente Lactobacillus y Bifidobacterium) y debe ser capaz de alterar la microbiota del colon hacia unas condiciones más saludables (Van der Meulen et al., 2006).

Es interesante considerar que una de las aplicaciones de las investigaciones de pre y probióticos con mayor potencial, es la formulación de alimentos simbióticos, y la leche ácida contienen tanto prebióticos como probióticos, los cuales son resultados de la administración conjunta de un prebiótico y de una bacteria probiótica, que se beneficia de la presencia en el medio luminal colónico de un sustrato específico, que le permite una mejor sobrevivencia y potencialmente beneficiaría la salud del paciente (Meléndez et al., 2011).

Debido al creciente interés de introducir productos lácteos fermentados con bacterias probióticas que aumenten el valor de su papel funcional, es una realidad actual y una apuesta a futuro para la innovación empresarial y la investigación en el campo de la alimentación. La leche ácida fermentada con Lactobacillus acidophilus es uno de estos productos, la cual ofrece un elevado valor nutritivo y diversos efectos benéficos sobre la salud; sin embargo, es necesario realizar más estudios en las diferentes cepas de Lactobacillus acidophilus para confirmar su funcionalidad probiótica. Los estudios sobre la capacidad probiótica del Lactobacillus acidophilus en la leche ácida han demostrado que posee propiedades de gran interés como en desórdenes intestinales a consecuencia de los microorganismos patógenos, estilos de vida, situaciones de estrés, ciertos hábitos en la dieta, la edad o tratamientos con antibióticos entre otros; hipercolesterolemia humana, el síndrome de la fatiga crónica, intolerancia a la lactosa y el cáncer al colon (Hati et al., 2019).

Los avances en la tecnología de su producción han permitido ofrecer al consumidor una gran variedad de tipos de leches fermentadas, con una calidad controlada y reproducible, esta incluye la selección y mejora de cultivos iniciadores que ha permitido optimizar las características metabólicas de las bacterias lácticas utilizadas en la fermentación, lo que ofrece mayor garantía de calidad y seguridad en el producto, e incluso en nuevos efectos beneficiosos para la salud (Tojo et al., 2006). Por lo que es importante evaluar la supervivencia de microorganismos probióticos como Lactobacillus acidophilus ya que dependen de las condiciones de estrés ambiental tales como: producción de peróxidos, producción de ácido láctico y acético, disponibilidad de nutrientes y temperatura de incubación (Krasaekoopt y Watcharapoka, 2014), lo que nos motiva a optimizar los parámetros de fermentación de la leche ácida.

Cada vez el uso de alimentos nutracéuticos es prioritario, debido a sus beneficios para la salud y uno de ellos son los probióticos y el empleo de matrices vegetales (frutas) es un desafío para la agricultura, demostrando ser excelentes sustratos para el crecimiento de probióticos, ya que son prebióticos que permiten el desarrollo de bebidas nutracéuticas. Perú es un país productor de una gran variedad de frutas, con las que se pueden plantear estrategias y alternativas para el aprovechamiento de los recursos de la biodiversidad (Bernal et al., 2017). 
Debido a estas virtudes que nos ofrece la leche ácida, se evaluaron los parámetros de fermentación en los cuales pueda realizar la bacteria una óptima fermentación utilizando como sustrato a la leche y ofrecernos así un producto de calidad que sea capaz de fortalecer la flora microbiana del sistema digestivo. Los objetivos de la investigación fueron: optimizar los parámetros de fermentación para la elaboración de leche ácida con Lactobacillus acidophilus, optimizar el empleo del tipo y concentración de agentes conservantes y realizar el control de calidad del producto elaborado con la pulpa de durazno y chirimoya.

\section{METODOLOGÍA}

La investigación se realizó en el Laboratorio de Biotecnología Microbiana de la Universidad Nacional de San Cristóbal de Huamanga, y la metodología se presenta en varias subsecciones que siguen una secuencia lógica.

\section{Obtención de la materia prima}

Se utilizó como materia prima la leche de vaca, la cual se adquirió de tres lecherías de la ciudad de Ayacucho, encontrándose en condiciones de refrigeración, con un $\mathrm{pH}$ 6.5, color, sabor y olor característico. La cepa de Lactobacillus acidophilus utilizada fue aislada en la investigación (Flores, 2008) a partir de chicha de molle e identificada mediante la fermentación de azúcares en base al Manual de Bergery's.

\section{Estandarización de la carga microbiana}

La estandarización de la carga microbiana de Lactobacillus acidophilus se realizó por el método de espectrofotometría y el recuento estándar en placa (Carrasco, 2017). Se utilizó un espectrofotómetro de marca Milton Roy modelo 20D. Se suspendió la cepa de Lactobacillus acidophilus en 3 tubos con $5 \mathrm{ml}$ de Caldo Lactobacilli, luego se incubó a $37^{\circ} \mathrm{C}$ por intervalos de tiempo de 5, 15 y 30 minutos, leyéndose la absorbancia a $640 \mathrm{~nm}$, la cual es proporcional a la concentración de células en suspensión. Inmediatamente después se realizaron diluciones sucesivas hasta $10^{4}, 10^{6}$ y $10^{8} \mathrm{UFC} / \mathrm{ml}$, las cuales fueron sembradas por incorporación en Agar Lactobacilli. Estas placas fueron incubadas a $37^{\circ} \mathrm{C}$ por $24 \mathrm{~h}$ y luego se realizó el recuento de colonias.

\section{Optimización de los parámetros para la elaboración de leche ácida}

Se procedió a pasteurizar la leche fresca a $72^{\circ} \mathrm{C}$ durante 15 minutos, luego se dejó enfriar y con la ayuda del lactodensímetro se leyó la densidad de la leche que debe encontrarse en un rango de 1,029 - 1,032; luego se realizó la lectura del pH que debe estar entre 6,0-6,5. Se inoculó el $5 \% \mathrm{v} / \mathrm{v}$ del cultivo de Lactobacillus acidophilus en concentraciones de $10^{6}, 10^{8}$ y $10^{10} \mathrm{UFC} / \mathrm{ml}$ a la leche que se encontraba a $43^{\circ} \mathrm{C}$. Estas muestras fueron incubadas a 42,45 y $50 \stackrel{\circ}{C}$ por 8,10 y 12 h y después de la incubación se llevó a una temperatura de $4^{\circ} \mathrm{C}$ por $2 \mathrm{~h}$, finalmente se realizó un ligero batido y se determinó el pH.

\section{Elaboración de pulpa jarabeada}

Para elaborar la pulpa jarabeada se procedió a lavar $1 \mathrm{Kg}$ de fruta de durazno de la variedad "huayco" y chirimoya de la variedad "cumbe", las que se pelaron y trozaron para luego ser licuadas, se adicionó el $50 \%$ $\mathrm{p} / \mathrm{p}$ de azúcar, se pasteurizó a $75^{\circ} \mathrm{C}$ por $25 \mathrm{~min}$, se dejó enfriar, se colocó a $4{ }^{\circ} \mathrm{C}$ y al producto final se le agregó el $5 \% \mathrm{v} / \mathrm{v}$ de la pulpa de fruta.

\section{Análisis bromatológico de la leche ácida}

Se tomó en cuenta las normas de la A.O.A.C. (2016) para leche y productos lácteos. Determinándose: 1) La humedad y peso seco por el método Gravimétrico; 2) Cenizas por medio del método de la incineración indirecta; 3) Proteína por el método de Micro-Kjeldahl; 4) Grasa por el método de Gerber; 4) Carbohidratos totales por el método directo y 5) Valor energético y valor nutricional por el método de Added Water.

\section{Análisis de agentes conservantes y microbiológicos de la leche ácida}

Se realizó el análisis de viabilidad con y sin refrigeración, con o sin agentes conservantes. Para este último se utilizó dos agentes conservantes el benzoato de sodio y sorbato de potasio distribuidos en 7 tratamientos (Tabla 1). Para el análisis microbiológico se tomó en cuenta las normas establecidas para Leches Fermentadas del Codex Alimentarius (2006), las cuales exigen un análisis de cuantificación de coliformes totales y fecales, salmonella, mohos y levaduras (MINSA, 2008). 
Tabla 1: Agentes conservantes para la evaluación de la viabilidad de Lactobacillus acidophilus

\begin{tabular}{|c|l|}
\hline Tratamiento & \multicolumn{1}{|c|}{ Agente preservante } \\
\hline 1 & $0,1 \%$ de benzoato de sodio \\
\hline 2 & $0,1 \%$ de sorbato de potasio \\
\hline 3 & $0,05 \%$ de benzoato sodio $+0,05$ sorbato de potasio \\
\hline 4 & $0,05 \%$ de benzoato de sodio \\
\hline 5 & $0,05 \%$ de sorbato de potasio \\
\hline 6 & $0,025 \%$ de benzoato de sodio $+0,025 \%$ de sorbato de potasio \\
\hline 7 & Control \\
\hline
\end{tabular}

\section{Análisis sensorial de la leche ácida}

El examen sensorial (organoléptico), se llevó a cabo por el método de graduación; de muy malo hasta excelente, codificados como sigue: $1=$ muy malo, $2=$ malo, $3=$ regular, $4=$ bueno y $5=$ excelente. Se aplicó una encuesta a 81 personas que tenían un rango de edad entre $18-70$ años.

\section{Análisis estadístico}

Los resultados obtenidos fueron sometidos a un análisis de varianza factorial $\mathrm{A} \times \mathrm{B} \times \mathrm{C}(3 \times 3 \times 3)$ con un nivel de significancia de $\alpha=0,05$. Se utilizó el paquete estadístico SPSS versión 23. Para los resultados de las encuestas se aplicaron tablas de frecuencias.

\section{RESULTADOS Y DISCUSIÓN}

La estandarización de la carga microbiana se realizó mediante la técnica de espectrofotometría y comparada con el recuento estándar en placa (García-Godos, 2017), la cual está basada en la determinación de la densidad óptica, siendo proporcional a la masa de las partículas en suspensión (células); obteniendo una carga microbiana de $10^{6} \mathrm{UFC} / \mathrm{ml}$ con una absorbancia de 0,136 en un periodo de incubación de 10 min,; para una carga de $10^{8} \mathrm{UFC} / \mathrm{ml}$ con una absorbancia de 0,245 en un periodo de $15 \mathrm{~min}$,; y para una carga de $10^{10}$ UFC/ml con una absorbancia de 0,305 en un periodo de incubación de 30 minutos, valores que coinciden con lo determinado por (Flores, 2008), reportando que a una carga microbiana de $10^{6} \mathrm{UFC} / \mathrm{ml}$ con una absorbancia de 0,137 en un periodo de incubación de $4 \mathrm{~h}$ y para $10^{8} \mathrm{UFC} / \mathrm{ml}$ con una absorbancia entre 0,150 $-0,195$ en un periodo de 5 a 6 horas; se evidencia que existe una diferencia en el tiempo de incubación esto se debe a la cantidad de inóculo sembrado en el caldo de cultivo inicial.

Para la optimización de los parámetros de fermentación y determinación del pH final de la leche ácida, se inoculó cargas microbianas de $10^{6,} 10^{8}$ y $10^{10} \mathrm{UFC} / \mathrm{ml}$ de Lactobacillus acidophilus, incubándose a 42,45 y $50 \stackrel{\circ}{\circ}$ por 8,10 y 12 horas, observando que con una inoculación de $10^{8} \mathrm{UFC} / \mathrm{ml}$ y una incubación a $45^{\circ} \mathrm{C}$ por 8 horas, se obtuvo un pH final de 4,5 (Tabla 2) con una desviación estándar de 0.0416 y una acidez titulable de $90 \stackrel{\circ}{\circ}$ correspondiente a $0,9 \%$ de ácido láctico y una carga microbiana final de $10^{15} \mathrm{UFC} / \mathrm{ml}$. Resultados que coinciden con las investigaciones de (Raftaniamiri et al., 2010), que para la producción de leche ácida utilizó Lactobacillus acidophilus NCDC $N^{\circ} 015$, leche pasteurizada a la que se añadió leche descremada en polvo 3\% (Amul), inulina 10\%, fibra de avena $0,2 \%$ y miel $7 \%$; dejándolo incubar a $40^{\circ} \mathrm{C}$ de 4 a 4,5 horas obteniendo un pH final de 4,7. Mientras que (Junaid et al., 2013) para la producción de leche ácida inóculo de $1-5 \%$, a una temperatura de $30-40^{\circ} \mathrm{C}$ y con un tiempo de incubación de $4-8$ horas, obteniendo un $\mathrm{pH}$ final de 4,4. En tanto que (Hernández, 2005) elaboró leche ácida, en la que utilizó leche UHT, una cepa de Lactobacillus acidophilus del cultivo VIVOLAC, con una temperatura de incubación de 42 $-45^{\circ} \mathrm{C}$, resultando que al final de la fermentación alcanzó un $\mathrm{pH}$ de 4,8 con $70^{\circ} \mathrm{D}$, sin embargo después del baño de agua con hielo y conservada bajo $6-10^{\circ} \mathrm{C}$ durante 12 horas esta llegó a obtener un pH final de 4,5 con una acidez igual a $85 \stackrel{\circ}{\circ}$, mientras que (Ramírez y Vélez, 2016) manifiestan que mejorando el control sobre los procesos, la vida útil y la calidad microbiológica del producto lácteo terminado se incrementa el desempeño de las cepas lácticas, en base a estos resultados es fundamental determinar los parámetros óptimos de fermentación de la leche ácida con la bacteria $L$. acidophilus, ya que permitirá obtener un producto de calidad y con estabilidad con características aceptadas para el consumidor.

Respecto a la cuantificación de la carga microbiana de Lactobacillus acidophilus en investigaciones como la de (Lovayová et al., 2015), quienes manifiestan que en los alimentos probióticos como yogur, kéfir y quesos reportaron al inicio de la fermentación una carga microbiana de $10^{7} \mathrm{UFC} / \mathrm{ml}$, en el transcurso y término de la fermentación se obtuvo $10^{15} \mathrm{UFC} / \mathrm{ml}$, manteniéndose estable hasta más de 180 días, mientras que (Obando et al., 2010), señala que el $L$. acidophilus es el probiótico que menos viabilidad pierde (menor a 0,5 ciclos logarítmicos) durante 21 días de almacenamiento en productos lácteos, siendo el pH uno de los factores 
más importantes que restringen la viabilidad de la bacteria probiótica, este crecimiento termina con un $\mathrm{pH}$ debajo de 4,0 (Verdenelli et al., 2009), y en la investigación el producto final de la leche ácida obtuvo un pH 4,5, parámetro favorable para mantener constante la viabilidad del probiótico, ya que bajo éstas características la bebida probiótica tiene un rol en la dieta saludable comportándose como un alimento funcional en la prevención de enfermedades.

Tabla 2: pH final de la leche ácida en diferentes cargas microbianas de Lactobacillus acidophilus

\begin{tabular}{|c|c|c|c|c|}
\hline \multirow{2}{*}{$\begin{array}{c}\text { Carga Microbiana } \\
\text { UFC/ml }\end{array}$} & \multirow{2}{*}{$\begin{array}{l}\text { Tiempo } \\
\text { (horas) }\end{array}$} & \multicolumn{3}{|c|}{ Temperatura $\left({ }^{\circ} \mathrm{C}\right)$} \\
\hline & & 42 & 45 & 50 \\
\hline \multirow[t]{3}{*}{$10^{6}$} & 8 & 4,90 & 4,80 & 4,60 \\
\hline & 10 & 4,90 & 4,77 & 4,90 \\
\hline & 12 & 4,90 & 4,87 & 4,90 \\
\hline \multirow[t]{3}{*}{$10^{8}$} & 8 & 4,90 & 4,50 & 4,60 \\
\hline & 10 & 4,87 & 4,30 & 4,77 \\
\hline & 12 & 4,83 & 4,27 & 4,83 \\
\hline \multirow[t]{3}{*}{$10^{10}$} & 8 & 4,90 & 4,80 & 4,60 \\
\hline & 10 & 5,00 & 4,57 & 4,90 \\
\hline & 12 & 5,00 & 4,60 & 4,87 \\
\hline
\end{tabular}

Con respecto al estudio de la vida anaquel del producto, se evaluó la conservación con y sin refrigeración en función del tiempo, obteniendo que el producto se conserva sin refrigeración hasta los 5 días, en cambio los conservados en refrigeración varía en función del sabor que presenta el producto, observándose que en forma natural (sin frutado) se conserva hasta 45 días, en relación al frutado de durazno y chirimoya que logran conservarse por 25 y 21 días respectivamente, (Tabla N 3), es necesario remarcar que los productos probióticos, como es el caso de la lecha ácida por la presencia de bacterias ácido lácticas, las que producen bacteriocinas y siendo estas sustancias antibactericidas, realizan la función de agente conservante frente a microorganismos patógenos y también el producto presenta un $\mathrm{pH}$ de 4 y una acidez de $90^{\circ} \mathrm{D}$, estos dos parámetros se comportan como barrera evitando la contaminación microbiana, finalmente el ácido láctico producido en la fermentación y el pH final ayudan en la conservación de la leche ácida con refrigeración. Esto se fundamenta en base a que una de las líneas de aplicación de las bacteriocinas de interés en la industria alimentaria se basa en su carácter biopreservativo (Eckner et al., 1992) y la producción de ácido durante la fermentación impide el crecimiento de microorganismos patógenos al igual que el pH (entre $4-5$ ), se menciona que con valores más bajos los microorganismos se tornan más sensibles a otras medidas de control microbiológico.

Tabla 3: Conservación de la leche ácida elaborado con Lactobacillus acidophilus

\begin{tabular}{|l|c|c|}
\hline \multicolumn{1}{|c|}{ Lecha ácida } & $\begin{array}{c}\text { Sin refrigeración } \\
\text { (días) }\end{array}$ & $\begin{array}{c}\text { Con refrigeración } \\
\text { (días) }\end{array}$ \\
\hline Natural & 5 & 45 \\
\hline Durazno & 5 & 25 \\
\hline Chirimoya & 5 & 21 \\
\hline
\end{tabular}

Como resultado del análisis bromatológico de la leche ácida se reportó el porcentaje de proteínas de 4,59\% (natural), 4,34\% (chirimoya) y 3,57\% (durazno) (Tabla 4) que a comparación con el estudio realizado por (Reyes et al., 2018) para el yogurt fue $4,1 \%$ de proteína, siendo inferior al obtenido por la leche ácida de sabor natural. En cuanto se refiere al porcentaje de grasa, la leche ácida reporta el $1 \%$ (natural), 1,5\% (chirimoya) y 1,3\% (durazno) y con respecto a la evaluación de calorías se obtuvo 59,92 Kcal para la leche ácida natural, 105,74 Kcal sabor durazno y 110,74 Kcal sabor de chirimoya, estos valores nutricionales son similares a los yogures comerciales, conocemos que el valor nutricional, establece el aporte nutricional que nos proporciona un alimento para ser considerado como ideal, por lo que la leche ácida presenta un alto porcentaje de Kcal en comparación con lo mencionado por (Reyes et al., 2018) (3,62 Kcal), esta diferencia se debe al tipo de pasteurización utilizada, en el caso de la investigación utilizamos leche pasteurizada a una temperatura $\left(<85^{\circ} \mathrm{C}\right)$ por un periodo de 7 minutos; mientras que los yogures comerciales son elaborados con leche UHT y pasteurizados a una temperatura muy elevada por un periodo muy corto $(140 \stackrel{\circ}{\circ}$ por $6-10$ segundos), teniendo la ventaja en la conservación de las características iniciales como las proteínas, y la prolongación de la vida anaquel de hasta dos meses sin refrigeración, observando que la lecha ácida natural o frutada cumple con las normas del Codex Alimentarius con respecto a la composición bromatológica. 
Los índices microbiológicos para la leche ácida denotaron excelente calidad higiénica sanitaria durante el periodo evaluado y en el producto final, esto se debe a la presencia de bacteriocinas y a la formación del ácido láctico en la fermentación (Sreekumar y Hosono, 2000), siendo estos considerados como agentes potenciales para preservar los alimentos.

Tabla 4: Análisis bromatológico de la leche ácida

\begin{tabular}{|l|l|c|c|c|c|c|c|c|}
\hline \multicolumn{2}{|l|}{ Producto } & $\begin{array}{c}\text { Humedad } \\
(\%)\end{array}$ & $\begin{array}{c}\text { Prot } \\
(\%)\end{array}$ & $\begin{array}{c}\text { Grasa } \\
(\%)\end{array}$ & $\begin{array}{c}\text { Carb } \\
(\%)\end{array}$ & $\begin{array}{c}\text { Cenizas } \\
(\%)\end{array}$ & $\begin{array}{c}\text { V.C. Valor calórico } \\
\text { Kcal/100g }\end{array}$ & $\begin{array}{c}\text { V.N. Valor Nutritivo } \\
\text { Kcal }\end{array}$ \\
\hline \multirow{3}{*}{ Leche ácida a } & Natural & 85,39 & 4,59 & 1,00 & 8,14 & 0,88 & 59,92 & 4,78 \\
\cline { 2 - 9 } & Durazno & 74,60 & 3,57 & 1,30 & 19,94 & 0,59 & 105,74 & 14,28 \\
\cline { 2 - 9 } & Chirimoya & 73,60 & 4,34 & 1,50 & 19,79 & 0,67 & 110,74 & 11,77 \\
\hline
\end{tabular}

Con el fin de determinar la acción de los agentes conservantes químicos para ampliar la vida anaquel sin refrigeración se estudió dos tipos de agentes conservantes el benzoato de sodio y sorbato de potasio, utilizados solos, ambos y a diferentes concentraciones, para lo cual se evaluó la carga microbiana en función del tiempo, observando que en los siete tratamientos utilizados almacenados sin refrigeración y con una carga microbiana inicial de $10^{10} \mathrm{UFC} / \mathrm{ml}$ se reporta una carga microbiana de $10^{9} \mathrm{UFC} / \mathrm{ml}$ hasta los 35 días de evaluación para los sabores de durazno y chirimoya, valores similares a los tratamientos de leche ácida almacenados con refrigeración, pero con respecto al control, es decir sin la adición de agentes conservantes se observa una carga de $10^{28} \mathrm{UFC} / \mathrm{ml}$ y $10^{15} \mathrm{UFC} / \mathrm{ml}$ sin y con respectivamente (Tabla 5), lo cual no es recomendable debido a que si se presenta mayor carga microbiana, existe mayor acidez y por ende cambia las características organolépticas deteriorando la leche ácida. Finalmente para determinar que tratamiento de agentes conservantes fue el mejor se evaluó la aceptación de los siete tratamientos y del análisis estadístico refiere que existen diferencias estadísticas resultando que el Tratamiento 1, el cual está compuesto por 0,1\% de benzoato de sodio presentó un $98 \%$ de aceptación y para los almacenados en refrigeración los tratamientos 1 y 2 ( $0,1 \%$ de benzoato de sodio y $0,1 \%$ sorbato de potasio) presentaron el $100 \%$ de aceptación y una carga microbiana de $10^{9} \mathrm{UFC} / \mathrm{ml}$, parámetro que está por encima de lo establecido para ser considerado como un alimento probiótico, con respecto a ello el (Codex Alimentarius, 2011) manifiesta que la viabilidad de los microorganismos en un producto probiótico durante toda la vida útil es imprescindible porque condiciona su actividad, el número de células al final de su vida útil debe ser de al menos $10^{7} \mathrm{UFC} / \mathrm{ml}$.

Tabla 5: Evaluación de la carga microbiana (UFC/ml) de la leche ácida en diferentes tratamientos de agentes conservantes ( $\left.{ }^{*}\right)$ Carga microbiana inicial de $10^{10} \mathrm{UFC} / \mathrm{ml}$

\begin{tabular}{|c|c|c|c|c|c|c|c|c|c|}
\hline \multirow[t]{3}{*}{ Sabor } & \multirow[t]{3}{*}{ Tratamiento } & \multicolumn{8}{|c|}{ Días } \\
\hline & & \multicolumn{4}{|c|}{ Sin refrigeración } & \multicolumn{4}{|c|}{ Con refrigeración } \\
\hline & & 5 & 15 & 25 & 35 & 5 & 15 & 25 & 35 \\
\hline \multirow[t]{7}{*}{ Durazno } & 1 & $10^{6}$ & $10^{6}$ & $10^{8}$ & $10^{9}$ & $10^{6}$ & $10^{9}$ & $10^{9}$ & $10^{9}$ \\
\hline & 2 & $10^{6}$ & $10^{6}$ & $10^{8}$ & $10^{8}$ & $10^{6}$ & $10^{9}$ & $10^{9}$ & $10^{9}$ \\
\hline & 3 & $10^{6}$ & $10^{6}$ & $10^{8}$ & $10^{9}$ & $10^{6}$ & $10^{9}$ & $10^{9}$ & $10^{9}$ \\
\hline & 4 & $10^{6}$ & $10^{6}$ & $10^{8}$ & $10^{9}$ & $10^{6}$ & $10^{9}$ & $10^{9}$ & $10^{9}$ \\
\hline & 5 & $10^{6}$ & $10^{6}$ & $10^{6}$ & $10^{9}$ & $10^{6}$ & $10^{9}$ & $10^{9}$ & $10^{9}$ \\
\hline & 6 & $10^{6}$ & $10^{6}$ & $10^{6}$ & $10^{9}$ & $10^{6}$ & $10^{9}$ & $10^{9}$ & $10^{9}$ \\
\hline & 7 & $10^{28}$ & $10^{28}$ & $10^{28}$ & $10^{28}$ & $10^{15}$ & $10^{15}$ & $10^{14}$ & $10^{15}$ \\
\hline \multirow[t]{7}{*}{ Chirimoya } & 1 & $10^{6}$ & $10^{6}$ & $10^{8}$ & $10^{9}$ & $10^{6}$ & $10^{9}$ & $10^{9}$ & $10^{9}$ \\
\hline & 2 & $10^{6}$ & $10^{6}$ & $10^{8}$ & $10^{8}$ & $10^{6}$ & $10^{9}$ & $10^{9}$ & $10^{9}$ \\
\hline & 3 & $10^{6}$ & $10^{6}$ & $10^{8}$ & $10^{9}$ & $10^{6}$ & $10^{9}$ & $10^{9}$ & $10^{9}$ \\
\hline & 4 & $10^{6}$ & $10^{6}$ & $10^{8}$ & $10^{9}$ & $10^{6}$ & $10^{9}$ & $10^{9}$ & $10^{9}$ \\
\hline & 5 & $10^{6}$ & $10^{6}$ & $10^{6}$ & $10^{9}$ & $10^{6}$ & $10^{9}$ & $10^{9}$ & $10^{9}$ \\
\hline & 6 & $10^{6}$ & $10^{6}$ & $10^{6}$ & $10^{9}$ & $10^{6}$ & $10^{9}$ & $10^{9}$ & $10^{9}$ \\
\hline & 7 & $10^{6}$ & $10^{6}$ & $10^{8}$ & $10^{9}$ & $10^{6}$ & $10^{9}$ & $10^{9}$ & $10^{9}$ \\
\hline
\end{tabular}

Para poder evaluar la aceptación del producto se realizaron pruebas de degustación, las cuales se desarrollaron mediante una encuesta a 81 personas siendo una muestra heterogénea, constituida por docentes y estudiantes de la universidad, se empleó una escala de 5 categorías: muy bueno, bueno, regular, malo y muy malo, observando que el $88 \%$ la categorizaron como muy buena y $12 \%$ como buena, y al determinar la preferencia del sabor el $46,9 \%$ eligieron al sabor a chirimoya, el $40,7 \%$ el sabor a durazno y el $12,4 \%$ prefirieron ambos sabores. Mientras que (Villegas, 2012) en su estudio de degustación de la leche ácida presentada en dos tipos de sabores (durazno y zarzamora) en donde participaron 59 personas del total 
$81,7 \%$ eran estudiantes, $10 \%$ empleados, 3,3\% profesores y $5 \%$ tesistas, mostrando que para ambos sabores la calificación de bueno a excelente (Figura 1). Como resultado de la encuesta se podría revelar que es posible la introducción de este nuevo producto debido a su agradable sabor (cuando es adicionada la pulpa de frutas o sólo con la adición de un porcentaje de azúcar) y sus efectos benéficos que posee este producto probiótico ya mencionado en múltiples estudios realizados, como por ejemplo, lo señala (Gonzáles et al., 2015) la leche ácida, yogur o leches fermentadas pueden ser utilizadas como vehículos para la incorporación de probióticos en la dieta.

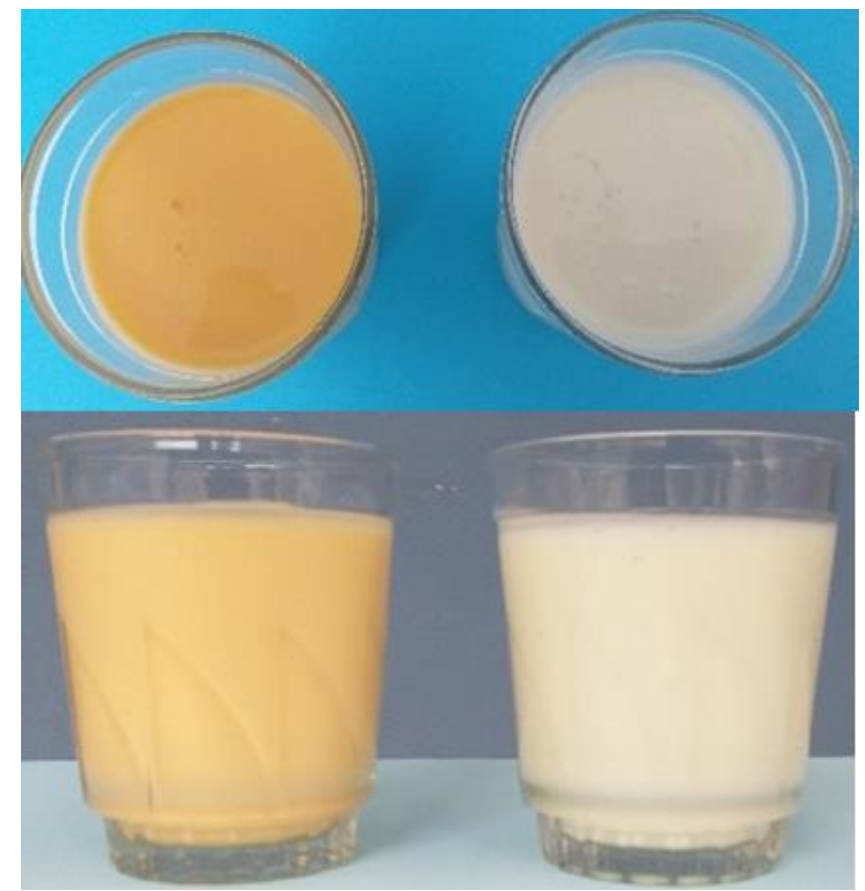

Fig. 1: Leche ácida de sabor durazno y chirimoya

Actualmente existen retos biotecnológicos para asegurar la viabilidad, estabilidad en el almacenamiento y efectos sensoriales de productos fermentados a partir de leche y vegetales con potenciales características probióticas. Con respecto a la leche y sus derivados (Conti et al., 2012) manifiesta que presentan un gran potencial para la formulación de bebidas funcionales como la leche ácida que específicamente diseñadas, contienen los niveles y calidad de proteínas requeridos. En el mercado existe un interés por los alimentos funcionales por el desarrollo de bebidas a base de frutas enriquecidas con probióticos y prebióticos, en base a la existencia de sustratos ideales para las cepas de probióticos y fuentes de prebióticos, debido a que contienen agua, minerales, vitaminas, fibra dietaria y antioxidantes, por ser consideradas por los consumidores como bebidas nutritivas y refrescantes, por lo que la tendencia es de realizar estudios de bebidas funcionales utilizando como sustrato frutas exóticas o de origen tropical.

\section{CONCLUSIONES}

De acuerdo a los resultados de la investigación y la comparación con resultados de otros autores y del detallado análisis se plantea cuatro conclusiones principales: 1) Se optimizó los parámetros para la elaboración de leche ácida siendo, una inoculación de $10^{8} \mathrm{UFC} / \mathrm{ml}$ de Lactobacillus acidophilus, incubándose a $45^{\circ} \mathrm{C}$ por 8 horas, obteniendo el producto final con un $\mathrm{pH}$ de $4,5,0,9 \%$ de ácido láctico y una carga microbiana de $10^{15} \mathrm{UFC} / \mathrm{ml}$; 2) Se obtuvo la leche ácida natural con 4,59\% de proteínas, un valor calorífico de $59,92 \mathrm{Kcal} / 100 \mathrm{~g}$ y un valor nutricional de 4,78 Kcal.; 3) El mejor agente conservante para la elaboración de la leche ácida almacenada sin refrigeración fue el benzoato de sodio al $0,1 \%$, el cual presentó un $98 \%$ de aceptación y para los almacenados en refrigeración los tratamientos de benzoato de sodio y de sorbato de potasio al 0,1\% ambos, presentando el 100\% de aceptación, con una vida anaquel de 35 días y una carga microbiana de $10^{9} \mathrm{UFC} / \mathrm{ml}$, parámetro que está por encima de lo establecido para ser considerado como un alimento probiótico; y 4) Al realizar el control de calidad de la leche ácida elaborado con la pulpa de durazno y chirimoya, ésta cumple con lo establecido para ser considerada como apta para el consumo humano.

\section{AGRADECIMIENTOS}

Las autoras agradecen a la Universidad Nacional de San Cristóbal de Huamanga, por el apoyo para realizar la investigación. 


\section{REFERENCIAS}

A.O.A.C.: Official Methods of Analysis 20st Ed. Washintong-Estados Unidos (2016).

Bernal, C.A., Díaz-Moreno, C. y Gutiérrez-Cortés, C., Probióticos y prebióticos en matrices de origen vegetal: Avances en el desarrollo de bebidas de frutas, Rev Chil Nutr., 44 (4), 383-392 (2017).

Carrasco, J. y García-Godos P., Capacidad probiótica de bacterias lácticas aisladas de chicha de molle, Rev. Soc. Quím. Perú, 83(4), 391-402 (2017).

Codex Alimentarius: Norma del Codex para Leches fermentadas, 2st. Ed. FAO-OMS, Roma-Italia (2011)

Conti, J.P., Ceriani, M. C., Juliarena, M.A. y Esteban E.N., Perfil Proteico y Peptídico de una base Fluida para Bebidas Funcionales obtenida por Fermentación de Lactosuero, Información Tecnológica., 23(2), 61-70 (2012).

Eckner, K., Bacteriocins and food aplications. Dairy Food Environ, Sanit., 2(1), 204-211 (1992).

Farag, M.A., El Hawary E. A. y Elmassry M.M., Rediscovering acidophilus milk, its quality characteristics, manufacturing methods, flavor chemistry and nutritional value, J. Critical Reviews in Food Science and Nutrition, 59(1), 1-18 (2019).

Flores, M., Actividad probiótica del "yacón" Smallantus sonchifolia en el crecimiento poblacional del Lactobacillus acidophilus en ratas wistar. Tesis de Químico Farmacéutica, Universidad Nacional de San Cristóbal de Huamanga, Ayacucho, Perú (2008).

Gonzáles, R., Pérez, J. y Urbina N. A., Efecto de la microencapsulación sobre las propiedades reológicas y fisicoquímicas del Yogurt Blando, Información Tecnológica., 25(6), 45-56 (2014).

Hati, S., Das S. y Mandal S., Engineering Tools in the Beverage Industry: Technological advancement of functional fermented dairy beverages. 1ra Ed. (3) 101-136 Elsevier INC., Ámsterdam, Holanda (2019).

Junaid, M., Javed, I. y otros cinco autores, Development and quality assessment of flavored probiotic acidophilus milk. J. Anim. Plant Sci., 23(5), 1342-1348 (2013).

Kailasapathy, K. y Chin, J., Survival and therapeutic potential of probiotic organism with reference toLactobacillus acidophilus abd Bifidobacterium sp, Inmmunol Cell Biol., 78(1), 80-88 (2000).

Krasaekoopt, W. y Watcharapoka, S., Effect of addition of inulin and galactosachaccharude on the survival of microencapsulated probiotics in alginate beads coated with chitosan in simulated digestive system, yogurt and fruit juice, Food Sci Technol., 57(2), 761-766 (2014).

López-Rubio, A., Gavara, A. y Lagaron R., Bioactive packaging: turning foods into healthier foods through biomaterials, Trends Food Sci Technol., 17(10), 567-575 (2006).

Lovayová, V., Dudriková, E. y otros dos autores, Quantity of selected probiotic cultures in semi-hard cheese with lowcooking curd during the maturation process, J Food Sci Technol., 52(8), 4697-4702 (2015).

Meléndez, M., Aguilar, N. y otros dos autores, Compuestos prebióticos: de las moléculas al ser humano, Rev. Soc. Ven. Microbiol., 31(1), 6-12 (2011).

MINSA: Ministerio de Salud (Perú), Criterios Microbiológicos de Calidad Sanitaria e Inocuidad para los Alimentos y Bebidas de Consumo Humano, 591, Lima-Perú (2008).

Obando, C. M., Brito, C. C. S. y otros tres autores, Viability of the probiotic microorganisms Lactobacillus casei 01 , Lactobacillus acidophilus La-5, Bifidobacterium BB12 during cottage cheese shelf life, Vitae, 17(2), 141-148 (2010).

Raftaniamiri, Z., Khandelwal, P. y Aruna, B.R., Development of acidophilus milk via selected probiotics \& prebiotics using artificial neural network, Adv Biosci Biotech., 1, 224-231 (2010).

Ramírez, C. y Vélez-Ruíz, J., Aislamiento, Caracterización y Selección de Bacterias Lácticas Autóctonas de Leche y Queso Fresco Artesanal de Cabra, Información Tecnológica., 27(6), 115-128 (2016).

Reyes, M., Gómez-Sánchez, I. y Espinoza, C. Tablas peruanas de composición de alimentos,10 edic., Salud, Instituto Nacional de Nutrición, Lima-Perú (2018).

Sreekumar, O. y Hosono, A., Immediate effect of Lactobacillus acidophilus on the intestinal flora fecal enzymes of rats and the in vitro inhibition of E, coli en coculture, J Dairy Sci., 83(5), 931-993 (2000).

Tojo, R., Leis, R. y otros dos autores. Productos lácteos fermentados, An Pediatr Monogr., 4(1), 54-66 (2006).

Valdovino M.A., Montijob, E. y otros cuatro autores, Consenso mexicano sobre probióticos en Gastroenterología, Rev Mex Gastroenterología, 82(2), 156-178 (2017).

Van der Meulen R., Makras, L. y otros tres autores, In vitro kinetic analysis of oligofructose consumption by Bacteroides and Bifidobacterium spp. indicates different degradation mechanisms, Appl Environ Microbiol., 72(2), 1006-1012 (2006).

Verdenelli, M. C., Ghelfi, F. y otros cuatro autores, Probiotic properties of Lactobacillus rhamnosus and Lactobacillus paracasei isolated from human faeces. Eur J Nutr., 48(6), 355-363 (2009).

Villegas, A., Hernández-Espiñoza, N. y Hernández-Montes A., Evaluación de la calidad fisicoquímica y sensorial de una leche probiótica fermentada con Lactobacillus acidophilus. Ingeniería Agrícola y Biosistemas, 4(2), 69-75 (2012). 